\title{
Shades of pink and blue: Unidimensional spectra of identity within a multidimensional model of diversity.
}

Bobbi M. Woodhill

University of New England, Armidale, Australia;

Dr. Curtis A. Samuels

University of California, Berkeley.

\section{HIGHLIGHT}

- This article presents multidimensional aspects of identity as separate unidimensional spectra within a canalized range of variation.

- Examines complex spectrum theory to include gender and other facets of identity aligned along separate minimalist spectra.

- Provides a scientifically grounded yet simplistic contribution to visualizing the infinite expression of identity diversity more simplistically than currently possible.

- The model may assist in evaluating the shared developmental origins of all variation in human identities.

\section{Introduction}

Contemporary notions of human identity increasingly challenge traditional binary concepts, yet, despite identity's subdivision into numerous sub-categories and spectra, debate on how to represent and interrupt human identities' spectra remains.

\section{Aim}

Previous models of identity make it challenging to unravel Nature more simply. Minimalist spectra may allow for the location of this apparent complexity in identity more simply, yet without denying the complexity within. This article presents several aspects of identity, including gender, as lying within a canalized range of variation as separate spectra.

\section{Method}

Reviews complex spectrum theory to include gender and other facets of identity to pursue a novel minimalist theory of identity diversity aligned along separate yet interconnected spectra. 


\section{Conclusion}

We provide a scientifically grounded contribution to visualizing the infinite expression of identity diversity more simplistically and present several aspects of identity, including gender, as spectra lying within a canalized range of variation.

\section{Introduction}

"Navajo and Lakota cultures viewed sex as multifarious for centuries" (Treadwell, 2020, p. 92). Are sex and gender better theorized as binary, non-binary (Meyer-Bahlburg, 2019), or something else? When did the study of sex get so screwed up (Knowles \& Reed, 2019)? There has been a call for novel theories (Hyde et al., 2019), yet a valid, coherent, enduring, and utilitarian model for human diversity remains a challenge.

A spectrum of sex would help to attain Butlerian deconstruction of sex and gender into McKenna, and Kessler's (1977) nonexistence (Rosario, 2004). And several psychological theorists presented gender as a spectrum of learned behavior (Anne Constantinople, 1973; Jeanne Block, 1973; Sandra Bem, 1974). So began science's questioning of the validity of the binary model of gender in the measurement of masculinity and femininity.

Psychological instruments that measured masculinity and femininity had typically positioned them at the ends of a bipolar continuum. Anne Constantinople questioned this correlation between masculine and feminine behaviors and their biological dimorphism and proposed that masculinity and femininity were not unidimensional or metaphorically on a single spectrum instead of on separate bimodal continua (Constantinople, 1973). Simone de Beauvoir (1997) echoed the idea with her claim that one is not born a woman [or man] but instead becomes one.

\section{Nomenclature}

Avoiding the conflation of the categories of sex and gender (Francis, 2012) has inspired 21stcentury thinking, yet from scientific to lay communities, definitions of 'sex' and 'gender' remain divisive (Author $1 \& 2$ (a), 2021).

\section{Spectrum (plural spectra)}

Used to classify something in terms of its position on a scale between two extreme endpoints. This term is often used interchangeably with continuum/continua.

\section{Sex}

We are a sexually reproducing species, and much like the necessity to attain a patient's sex on admission to a hospital emergency department, this article will keep 'sex' as initially defined by Unger (1979) - the body's obvious physical and reproductive anatomy only (Author $1 \& 2$ (a), 2021). Under this model, the brain is a sexed organ.

\section{Gender}

This article maintains a separation of bodily sex separate from gender (see Author $1 \& 2$ (a) 2021). Maintaining the separation of sex and gender, yet with a caveat as we shall see, provides a reasoned account to Kaiser's (2012) dilemma of where does sex end and gender begin. This paper defines gender as cognitive but does not use it as a term for social expectations or social roles (see below). 


\section{Sexuality}

Sexuality is the interaction between sexual orientation and libido. It is variously flexible between masculine and feminine endpoints. Sexuality consists of sexual orientation (whom you are attracted to) and sexual drive (libido).

\section{Gender Roles}

Gender roles are unlike gender identity. Gender roles are learned behavior assigned by society and added to individual identity. They are more or less arbitrary.

\section{Dimorphic}

The term 'dimorphic,' meaning occurring in two distinct forms, is used in this article for significant differences with some overlap (McCarthy \& Konkle, 2005) and otherwise known as canalized.

\section{Canalized}

In this paper, canalized refers to discrete moderately focused male and female endpoints of a spectrum.

Most species maintain abundant genetic variation and experience a range of environmental conditions, yet phenotypic variation is low. That is, development is robust to changes in genotype and environment. It has been claimed that this robustness, termed canalization, evolves because of long-term natural selection for optimal phenotypes.

(Siegal \& Bergman, 2002, p. 10528).

Canalized psycho-neuroanatomy refers to that which is moderately focused on male and female endpoints depicting sex differences, i.e., psycho-neuroanatomy is canalized (Author $1 \& 2$ (a) 2021).

\section{The Need for a New Model}

The categories of male and female have been subdivided and widely accepted amongst lay communities as straight, lesbian, gay, bisexual, trans, and queer (LGBTQ).

Nevertheless, there are too many categories for researchers to study; "The field of gender identity is already overwhelmed with terminology" (Blanchard, 1989, p. 621) and further subdivision has led to muddled theory_and_labeling, e.g., non-binary, pansexual, demi-sexual, trans-masculine, trans-feminine, grey-gendered, poly-sexual, novo-sexual, maxi-gendered (Mardell, 2016). Such concepts are increasingly challenging to interpret despite the confidence they represent a widening variety of individual expression.

Any theory that brings some clarity into this discussion could be appealing and even better if it differentiated sexual motivation from sexual orientation (Imhoff et al., 2017) and sex from gender (Author $1 \& 2$ (a) 2021), and sexuality from gender roles.

\section{Original Spectrum Work}

Milton Diamond asserted that biological features everywhere are not always set with "on-off" switches or "black and white" characteristics. Aspects of sexuality, including sexual orientation and gender identity, may be regarded as arranged within a wide range of variation, more than merely male-female dichotomies (Diamond, 2009, p. 629). Given that everything based on genetic or hormonal development in human populations undeniably comes distributed along continua, it would be unsurprising to find sex and gender are not strictly binary (bimodal) or 
dichotomies; instead, each belongs to non-orthogonal ${ }^{1}$ biological continua as other authors have implied (McCarthy \& Arnold, 2011; Ellis, Hershberger, Field, Wersinger, Pellis, Geary, et al., 2008; Reeder, 2003). Such a sex and gender model obviates the need for reductionist or dichotomous thinking and anyone's characteristics can be anywhere on a continuum of variability (for example, height, color, weight, shoe size, hair length, health, etcetera). Pain also occurs along a continuum from nil to severe. Taken further, this suggests any individual identity may consist of any combination of sex, gender, sexuality, and non-essential behaviour. Of note, and what may at first appear counter-intuitive of continua, is that they "lend themselves to quantification and are well represented by statistical functions such as the normal distribution" (Haslam, 2002, p. 205). This parallels canalization theory represented in this paper and as "weakly bimodal" (Joel \& McCarthy, 2017, p. 381) with hyper-male on one endpoint, and hyperfemale on the other endpoint. What is more, imposing categorical binaries on phenomena that "vary by degrees along a dimension...fails to correspond to an underlying discontinuity, and there are no grounds for positioning [the phenomena] at any particular location along the continuum" (Haslam, 2002, p. 206).

Owing to the work of Waller and Meehl (1998), Carothers and Reiss (2013), and others, there is strong empirical support for sex and gender differences being dimensional or qualitative, i.e., they lie along spectra (Schudson, Dibble, \& van Anders, 2017). "The fluctuating levels of hormones and proteins during early fetal development confer a set of sexually dimorphic features as continuous variables on a spectrum" (O'Hanlan, K., Gordon, J., \& Sullivan, 2018, p. 35). Thus, following our canalization perspective, binary concepts of hypermasculine or hyperfeminine merely represent the furthest ends of a spectrum.

People as a total sample do not come in strictly discrete categories; instead, in all shapes and sizes across all races. Arguably strict 'categories' for homo sapiens possess little validity.

Nevertheless, the authority of binaries persists despite extensive medical evidence documenting biological profiles that do not fit neatly into male and female dichotomies (Ansara, 2010).

Where does sex end and gender begin (Kaiser, 2012)? A contemporary view of identity has the categories of male and female as 'discrete kinds' (Haslam, 2002); that is, there are no distinct categories of sex and gender. Instead, the categories are presented as graduations associated with all people generally, as variously linear and continuous, or circular and continuous, or dimorphic yet canalized towards female and male endpoints (Author $1 \& 2$ (a) 2021), or two-dimensional continua of genotypes and phenotypes (Rathus, Nevid, \& Fichner-Rathus, 2005).

\section{Problems Remain}

Spectra were introduced into the literature by Alfred Kinsey and his measurement of same sex attraction (Kinsey, Pomeroy, \& Martin, 1948/1979). Some now question the premise behind Kinsey's work and suggest there is more likely no single binary phenotype of sexual orientation (Ganna et al., 2019). In lay minds, masculinity and femininity continue to be categorically opposed (Vantieghem \&Vermeersch, 2014), and in academia there is still debate on how to represent and interpret dimensions vs. categories of identity.

Traditionally the sexes were distinguished by rather sharp nonarbitrary boundaries, and those boundaries were grounded by the lack of any $S R Y$ gene in an XX embryo (Haslam, 2002). However, the expression of non-binary bodily sex is observable in the intersex. Sex chromosome deviation in an otherwise $46 \mathrm{XX}$ or $46 \mathrm{XY}$ fetus during the critical window of sex differentiation

\footnotetext{
${ }^{1}$ Statistically meaning the items in question are overlapping or correlated. In this research, it means that sex and gender affect identity both together and separately.
} 
is typically associated with a spectrum of external genital development accounting for intersex individuals (Blackless et al., 2000).

Models of identity from the last century lacked sufficient subtlety to adequately describe the full diversity in human sexuality (Devor, 1994), while a spectrum model of difference removes the need for thinking in exclusively oppositional categories. It is clear, for example, that spectra distribute sexual orientation (Savin-Williams, 2014) and bodily sex is evident in intersex conditions (García-Acero et al., 2020), while others classify intersex as a phenotype, not a genotype (Wizeman \& Pardue, 2001) or both (Joel, 2012). Further for example, height is not only tall or short but exists on a spectrum between these two.

Could it be sex, gender, and sexuality are not strict dichotomies; instead, each belongs to nonorthogonal biological spectra as others have implied (McCarthy \& Arnold, 2011; Ellis et al., 2008; Rosario, 2004; Reeder, 2003)?

The full range of human diversity logically extends to virtually anything concerning the human condition, and if we are to describe identity diversity without pathologizing any, we may come to recognize an underlying simplicity.

\section{An Argument from Complexity-Simplicity}

Sexual Configuration Theory (SCT, van Anders, 2015) has shown its ability to capture more nuanced meanings in sexual partnerships, notably through its accommodation of personalized labelling of individual desires (Schudson et al., 2017). While Schudson et al. (2017) described some participants reported difficulty using the circular diagrams of SCT and that its complexity may make it challenging to researchers, others support it as a productive, valuable framework for understanding sexual minority individuals in qualitative research settings (Abed, Schudson, Gunther, Beischel, \& van Anders., 2019).

Another approach to examining identity diversity would be to seek out any natural simplicity amongst its apparent complexity. We may find direction from recalling Charles Darwin's claim that Nature's fundamental laws are simple, and simple on top of simple becomes complex. Novel minimalist spectra may allow us to represent Nature's apparent complexity more simply, yet without denying the complexity within.

The circular model of sexuality presented in SCT allows it to cover numerous individual possibilities. A minimalist spectrum model can do similarly while at the same time delineating additional intersecting separate spectra of identity as sex, gender, sexual orientation, libido, and gender roles, which are integrated into the whole person to form a complete individual identity. Accordingly, the complex intricacies of the social and cultural influences on sexuality that make it near impossible to fully explore (Ganna et al., 2019) can be more easily delineated with its biopsycho-social input.

\section{Reasoning backward}

Following the long-established scientific principle that understanding the 'usual' one must understand the 'unusual,' and accepting all LGBTQ individuals are legitimate natural identities and not necessarily pathological in themselves, leads one to ask what is common to all human development and how can we generalize to all identities.

The Law of Parsimony, or the Complexity-Simplicity Principle, is a conservative tool essentially promoting more straightforward solutions to seek understanding of complicated constructs and thereby reveal inherent structure (Smaling, 2005). The law is based on Ockham's Razor that states entities should not be multiplied without necessity. To paraphrase-science need not overwhelm us to the point of obscuring the overall pattern. 
Both the SCT and this current spectrum model allow for individuals to locate their sexuality (loosely defined) widely, be it heterosexual, exclusively homosexual, equally bisexual, or bisexual leaning more towards one sex or the other, or allosexual. Significantly, both models holistically account for bio-psycho-social input to flexibility. None of the spectra presented herein is unitary nor an isolated phenomenon; no one spectrum is privileged over another, and further, all spectra are interlinked. (Author $1 \& 2$, (b), in preparation).

Notably, different "theories may coexist while being differentially useful" (van Anders, 2015, p. 1184). SCT and spectrum theory do not contradict each other; instead, they are complementary and supporting.

\section{Spectra of everything}

The developmental-psycho-biological model of development proposes innately based templates of biology (genes, hormones, epigenetics) and psychology (cognitions and emotions) frame environmental differences (socially taught and learned differences. i.e., the practice of living itself (Joel, 2019; Jones \& Lopez, 2013; Hines, 2017; Eagly \& Wood, 2013).

$\mathrm{X}$ and $\mathrm{Y}$ chromosomes are the initial sex-specific factors that organize sex differences in development and adult phenotype (Arnold, 2009). Sexual differentiation occurs following XX or $\mathrm{XY}$ sex determination and the genetic sex of an individual determines the fate of bipotential gonads as either testis or ovaries (McCarthy, De Vries \& Forger, 2017). The presence of XX or $\mathrm{XY}$ gonads then determines the differential production of sex steroids, although genes, hormones, and postnatal social environment may interact. Epigenetic regulation of gene expression is exerted in both sexes throughout life (Joel et al., 2019). The combination of chromosomes, steroid hormones, and early neonatal experiences guide transient (enzymatic), stable (germline), single generation, multigenerational DNA patterns and epigenetic changes in the CNS.

Nevertheless, genetic expression is ultimately decided in the flexible and mailable DNA covering of the epigenome (reviewed in author $1 \& 2$ (b), in preparation). (see Degrees of variability later)

Spectrum theory holds that enough functional overlap in the expression of $\mathrm{X}$ and $\mathrm{Y}$-influenced genes occurs to create variance at the expressed level (Zietsch et al., 2008; McCarthy \& Arnold, 2011; Joel et al., 2015). This overlap is interpretative of the notion of canalization. The observation that not all male and female neuro-phyco-physiological differences are strictly dimorphic, nor all innate, nor stable over time (Hyde et al., 2019), warrants strictly dimorphic models be replaced by models that include the varied interacting influences on identity from hormones, genetics, epigenetics, personal psychology, and broader society (McCarthy \& Arnold, 2011).

To highlight how phenotypes founded on binary genotypes (chromosome complements) and hormones come not as separate categorical classes but are typically distributed along spectra, we can look to foetal alcohol syndrome (FAS), producing a wide range of irreversible effects on a developing foetus. The effects associated with FAS are classified along a spectrum of deformities (Rose, 2010). Further, for example, a phenotypic spectrum of genetic mutations are reported as causal of fertilization failure (infertility) in women (Lin et al., 2020). Autism spectrum disorder (ASD) is perhaps the most widely known phenotypic spectrum disorder. In ASD, epigenetic alterations likely play a key role in modulating the spectrum from high functioning to severe deficits in social communication and interaction (Rylaarsdam, \& Guemez-Gamboa, 2019).

Another example of variable phenotypic variation is the disorder anorexia nervosa (AN). Studies of AN have detected grey matter volume reduction and white matter microstructure alterations, mainly in regions of the prefrontal, parietal and temporal cortex, hippocampus, amygdala, insula, thalamus, and cerebellum. Notably, and in contrast to other phenotypic syndromes, most 
alterations associated with AN are reversible (Kappou et al., 2021). The researchers point out, "Of course, the complexity of both the human brain and the disease does not allow the definite attribution of a symptom to a specific area dysfunction" (Kappou et al., 2021, p. 29). This statement is an especially relevant one, given that due to functional connectivity, all regions in the brain do not work independently from one another but rather work together to execute psychological functions (Ao, Ouyang, Yang, \& Wang, 2021).

From a broad biological perspective, spectra of variability arguably encompass pathological and non-pathological states in human development. All human physiology can be expressed along spectra of variability, e.g., skin color, weight, bust size, shoe size, skeletal size, waist circumference, shoulder width, jaw structure, finger length, disease states, and etcetera. So why would not sex, gender, sexuality, and gender roles all fit into bio-psycho-social spectra?

\section{Taxa or Canalized spectra}

The sexes are likely not entirely binary nor entirely continuous, and gendered characteristics may not flow straightforwardly from them. Taxonomic data can assess valid categorical and dimensional structures (Ruscio \& Ruscio, 2008). Taxons are diagnostic of non-binary distinctions between the degrees of kind in question, i.e., taxa represent variation between individuals where phenotypic expression overlaps. The taxonomic method is a family of multivariate statistics useful in measuring non-binary distinctions (Haslam, 2002).

Despite gender as binary losing some of its usefulness (Meyer-Bahlburg, 2019), in the modern Anthropocene enough overlap in adult male and female 'categories' maintains they are dimensional, canalized, and representable via taxa (see figure 1).

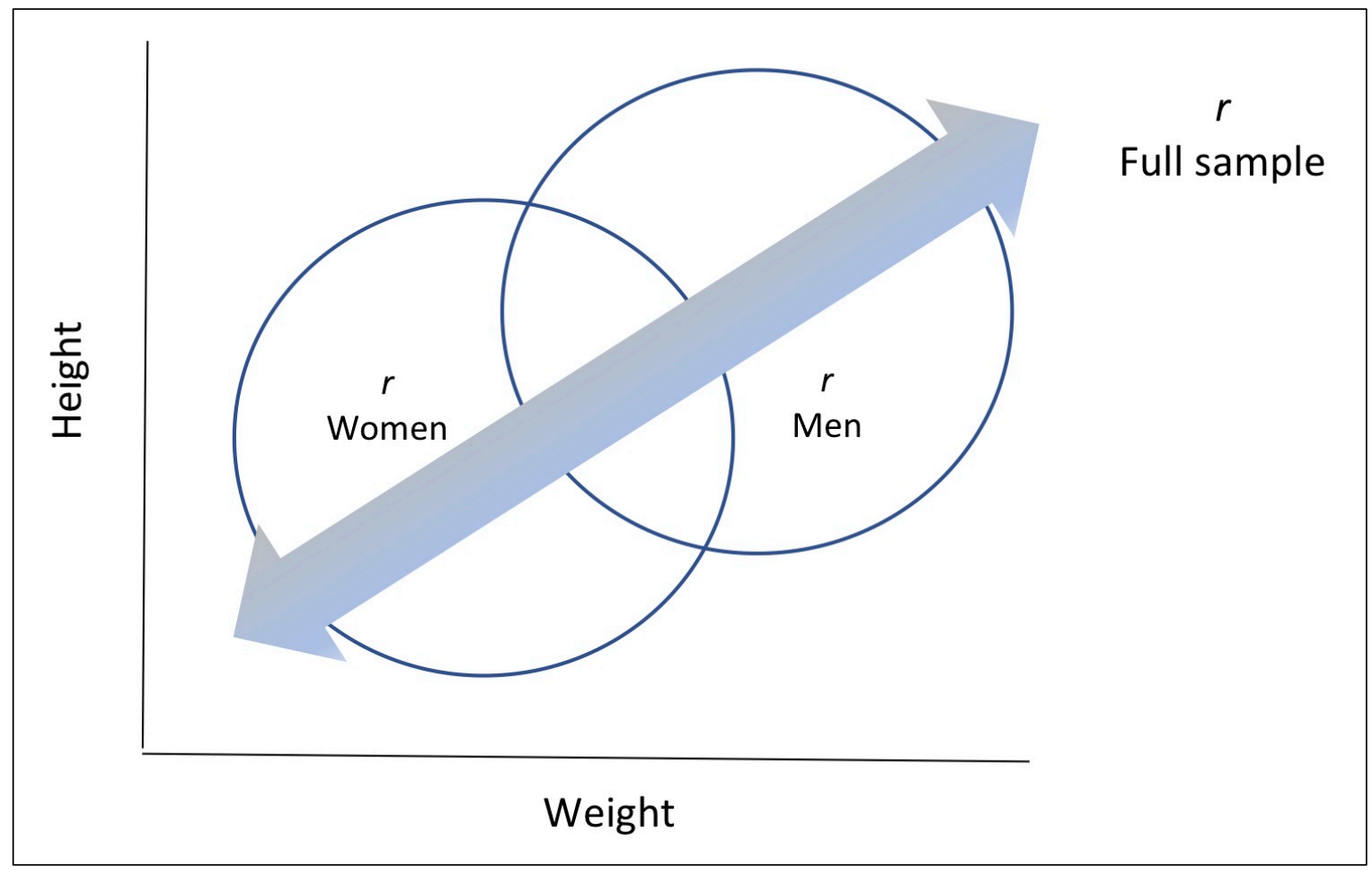

(insert figure 1 here)

Figure 1. Adapted from Carothers \& Reiss (2013). Men and women are from earth: Examining the latent structure of gender. Copyright Journal of Personality \& Social Psychology. Within-group versus full-sample correlation patterns underlying taxometric analysis. Within-group correlations tend to be small, but can be high over the full sample. Further adapted from Multivariate Taxometric Procedures: Distinguishing Types From Continua (p. 13, Figure 3.1), by N. Waller and P. Meehl, 1998, Thousand Oaks, CA: Sage. Copyright 1998 by Sage Publications. 
The notion of canalization is essential in distinguishing general behavior from that associated with reproductive behaviour (Author $1 \& 2$ (a) 2021). In what may seem contradictory to a spectrum model, McCarthy, Pickett, VanRyzin, and Kight (2015) comment canalization accounts for both the divergence and convergence of neuroanatomical endpoints. Margaret McCarthy proposes that,

...sex differences in the brain are [also] subject to canalization to assure [that] males and females are robustly different on multiple end points, but to also assure not too much. The sexes need to stay within range of each other.

(in Joel \& McCarthy, 2017, p. 382)

Outside the arena of reproduction, general behavior is an overlapping mosaic and more dependent on context, socialization, peer pressure, etcetera. Multiple regional brain inputs ultimately determine behavior (Author 1 \& 2 (a), 2021; McCarthy, Pickett, VanRyzin, \& Kight, 2015).

Though some researchers (Eliot, Ahmed, Khan, \& Patel, 2021; McCarthy et al, 2015) make no mention of, nor separate specific behaviors related to reproduction from general behavior, we can go on from their work to suggest that, like sex differences in neuroanatomical endpoints, the reproductive axis (RA) is divergent yet canalized to a sizable degree (Author $1 \& 2$ (a), 2021). However, the reproductive behaviors are not so divergent that the sexes are out of "range of each other" (Joel \& McCarthy, 2017, p. 382). Behaviors associated with the reproductive axis are not those referred to in models where the brain's higher-order executive functioning areas likely demonstrate the greatest male/female mosaic (Joel \& McCarthy, 2017; Rippon, G., JordanYoung, R., Kaiser, A., \& Fine., 2014). Higher-order executive functioning behaviors are "such as planning, working memory, inhibition, mental flexibility...emotional control, moral considerations, and processing of language" (Lotze et al., 2019, p. 5).

\section{Reproductive Behavior}

Within the framework of evolutionary theory, biological sex along with a set of gendered behaviors related to courtship, mating, offspring care, and often also territorial defense has evolved as a binary system that characterizes all mammalian species"

(Meyer-Bahlburg, 2019, p. 2028).

It is accepted that sex differences in behavior are related to reproduction (Joel \& McCarthy, 2017). Reproductive behaviors include those stemming from the reproductive axis, such as sexuality, courtship, mating, nurturance and empathy, common territorial defence, and resource gathering (Author $1 \& 2$ (a), 2021). Research suggests that most neuroanatomical development has occurred in-utero by around 5 to 6 months under the influence of differential fetal sex steroids (testosterone and estrogen) (Jones \& Lopez, 2013; Wu \& Shah, 2011). Significantly, estrogen and androgen receptors show high levels of distribution in the reproductive axis overall (Swaab, 2004; Sato et al., 2004; McEwen, 2001).

Just as the spectrum-like distribution of reproductive modes and intersex in the insect (Schon, Martens, \& van Dijk, 2009) and human worlds (Blackless et al., 2000) heralds the existence of spectra of human bodily sex, it follows gender canalization does not likely equal strictly dimorphic genders.

Overlapping means not strictly dimorphic, and it is simpler to visualize the overlap as canalized spectra. Canalization can then be defined as clustering towards but not beyond the ends of a spectrum. 


\section{The Usefulness of Spectra}

Representing variety along spectra allows us to illustrate any occurrence of variety. Spectra alleviate the need to construct identities out of nebulous concepts of human diversity. Spectra lend themselves to quantification and are well represented statistically by the normal distribution (Haslam, 2002). Furthermore, quantitative canalization can be statistically tested (Joel \& McCarthy, 2017; Joel et al., 2015).

Reproductive canalization evolved because of long-term natural selection for optimal phenotypes that followed (Siegal \& Bergman, 2002). Within a global spectrum model of identity-sex, gender, sexuality (outside reproductive biology (gametes - the XX ovum, XY spermatozoa) are separate unidimensional non-orthogonal (interrelated) spectra as other authors have implied (Reeder, 2003; Rosario, 2004).

\section{Canalized Spectra for Human Genotypes and Phenotypes}

Imagine a line that is white at one end and black at the other, as in figure 2 below.

(insert figure 2 here)

Figure 2.

Traveling from white to black, one must progress through infinite shades of grey (and yes, more than 50). Our imaginary line represents a spectrum, and for a more humanoid example, let us look at health. As a category, one is either healthy (a non-pathological state) or unhealthy (a pathological state), whereas a spectrum of health accounts for how one can feel anywhere inbetween healthy and unhealthy, that is, one can be anywhere along a spectrum of health from entirely healthy, just a little off-color as it were, or morbidly unwell. Arguably such variety can be extended to anything concerning human condition, and most significantly to identity's foundations - the body and brain.

Height as a human trait is more a case of quantitative variation along a continuum from tall to short rather than a categorical difference of either tall or short. As such, individuals can fall anywhere along that continuum. The Genetic Investigation of Anthropometric Traits (GIANT) Consortium, has shown selection pressure on 'height' and other traits such as skin color, birth weight, are influenced by local demographic polygenic selection, followed by phenotypic diversity between reproductive end points (McQuillan, Zhang, Tishkoff, \& Platt, 2020).

While we do classify people with the bipolar labels Tall and Short, and males and females are canalized towards separate ends - the normal distribution of male height is greater than the that of the female, one scholar asks might gender operate similarly and be both a binary and a spectrum (Reilly-Cooper, 2016). In other words, is gender canalized? While another claims a statistically rare occurrence [of intersex conditions] in the general population should not be considered typical enough to argue they are on a spectrum (Sow, 2018), we may claim sex and gender as canalized spectra are operating both at the canalized (figuratively bipolar) and spectrum level. 
While binary genotypes traditionally catalogue individuals as male and female with differentiated phenotypes, more succinctly, males and females are not strictly dimorphic, yet, canalized within narrow male and female phenotypes between endpoints relevant to the reproductive organs and reproduction (Author $1 \& 2$ (a) 2021). Joel (2012) presents a genetic-gonad-genital (3G-sex) model of identity that consists of both a genotype (genes, gonads, genitals) and phenotype (gender). This model's primary tenets are that identity is not entirely dimorphic nor consistent, and that gender is a social construct. In this model, sex differences in the brain and behavior are not dimorphic, and "having one brain/gender characteristic with the "male" form is not a reliable predictor for the form of other brain/gender characteristics" (p. 1).

In this current paper, we have accepted the different approach, that of a genotype that includes different biology for spectra of sex and gender, i.e., gender is biologically developed and innatereferred to by the authors as the 'reproductive axis model of gender' and built upon post-natally, hormonally, and socially (see Author $1 \& 2$ (a), 2021). The variety continues along each spectrum of sex, gender, sexuality, libido, and gender roles, from between groups of different sex, to within groups of the same sex.

One emerging principle is how steroid hormones mediate the organization of many different endpoints, e.g., sex behavior, maternal behavior, social play behavior, aggression, anxiety, learning strategies, etcetera (McCarthy \& Nugent, 2015), including variations across the female menstrual cycle and menopause (Zaidi, 2010). Nonetheless, differences related to mate choice and gender-roles based around sexual reproduction are the most robust. Notably, the further one moves away from differences related to reproduction, the less statistically significant and reliable are the differences (Diamond, 2009), and more significant overlapping of behavior becomes evident. So we can consider sex, gender, sexual orientation, and gender roles, as all existing along spectra within canalized reproductive endpoints.

\section{The Spectra}

The 'pink' ends represent all things female, and the 'blue' all things male along our imagined spectral line. There is an infinite range from pink through to blue that represents the variety apparent in all humans between these extremes. Myers (2008, p. 164) wrote, "Between day and night there is dusk, but between male and female there is . . essentially nothing". A spectrum model of identity would provide a physical dimension to Myers' theoretical 'dusk.'

Body Sex As A Spectrum

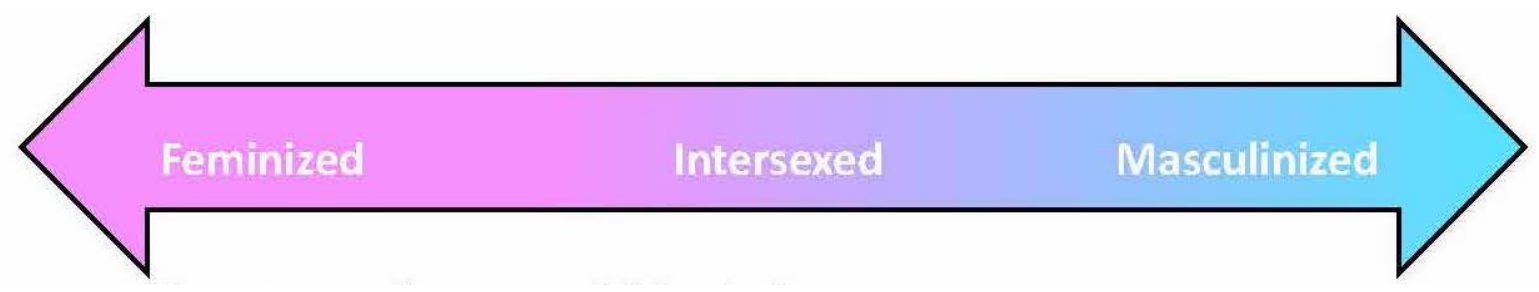

(insert figure 3 here)

Figure 3. Body sex as a biological spectrum - a genotype.

Genes determine gonads - the XX ovum, XY spermatozoa, that in turn determine body sex and evidenced by physical and reproductive anatomy. Mammalian bodily sex is differentiated prenatally yet, is not strictly dimorphic. Borrowing from Meyer-Bahlburg (2019), while it may be recognized XX / XY genetic binaries canalize differentiated taxons, the existence of intersex bodies, although rare, testifies to the overlapping of canalized bodily sex (García-Acero et al., 2020; Swaab \& Bao, 2016; Ainsworth, 2015). 
At the XX endpoint of bodily sex in figure 3, there are those whose bodies are especially pink. These are at the extreme feminine end of the spectrum; normally distributed as possessing a circular skull, wide eyes, small nose, small jawbone, narrow shoulders and waist, wide pelvic floor; light musculature; temple hair; small hands; third finger shorter than the first; and small feet.

At the extreme XY endpoint, there are those whose bodies are especially blue (very masculinized and normally distributed as possessing an oval skull, narrower eyes, larger nose, larger jawbone; broad shoulders, narrower pelvic floor, heavy musculature; little to no temple hair; large hands; third finger longer than the first; and large feet). In-between, there is an infinite variety of everyone else.

Essentially, in an XY genetic template, testosterone masculinizes the fetal reproductive [axis] at around nine weeks (Wang, Wu, \& Sun, 2019; Wizeman \& Pardue, 2001). Under the influence of the $S R Y$ gene on the Y chromosome, the fetal testes produce testosterone. An XY genetic template results in forming a male reproductive axis, including the gonads (Bao, \& Swaab, 2011) and the limbic system (Author $1 \& 2$ (a) 2021). Under an XX genetic template, and without the influence of any $S R Y$ gene on either $\mathrm{X}$ chromosome, comparatively little testosterone is produced by the adrenal glands as the enzyme aromatase (also called estrogen synthase) converts androgens to estrogens, which feminize the brain (Dodd et al., 2019; Bao \& Swaab, 2011). An XX genetic template results in forming a female reproductive axis, including the gonads (Bao, \& Swaab, 2011) and the limbic system (Author $1 \& 2$ (a) 2021).

With the production of testosterone by the fetal testes at around the ninth gestational week (Wizeman \& Pardue, 2001), an otherwise female embryo 'morphs' into a male (Guillamon, Junque, \& Gómez-Gil, 2016), although 'morphs' may be misleading as a natal female genotype requires two working copies of an X gene (Blecher, \& Erickson, 2007). More accurately, the sexdetermining region $(S R Y)$ on the male's Y chromosome is responsible for the formation of the testes. In the absence of the Y chromosome, ovaries develop (Simerly, 2010).

Reproductive bodies produce either sperm or eggs. Unreproductive bodies produce neither or versions incompatible with life. A significant deviation from endpoints in bodily sex is problematic and can lead to reproductive disorders and or a clash between body sex and gender in some cases, yet not in others (Wizeman et al., 2001). The intricate infographic presented in Montanez (2017) contains no representation of gender per se, nonetheless it illustrates the complicated networks within our simplistic spectrum of body sex and the input by chromosomes, genes, hormones, gonads, and secondary sex characteristics on the expression of typical and atypical sex development.

\section{Brain Sex - As Gender - As a Spectrum}

Generalized confusion regarding gender identity has resulted from conflating biological sex (the body's physical and reproductive anatomy), brain sex (innate gender), and gender roles (as learned behaviour).

“...regardless of the academic discussions about one-dimensionality, two-dimensionality or multidimensionality, in people's heads, masculinity and femininity have been, are, and will continue to be each other's opposites."

(Vantieghem \&Vermeersch, 2014, p. 370).

The model of gender presented in this current paper returns it to the original spectrum where masculine and feminine are canalized endpoints of a single biological continuum, separate and removed from bodily sex, learned gender behavior, and gender roles, (Author $1 \& 2$ (a), 2021) 
Despite the general behavioural cognitive mosaic of cognitive behaviors unrelated to reproduction, gender identity here is presented as differential and tethered to behavior relevant to the RA, hardwired into the subsystems of the cortex and limbic system, and separate to higherorder executive functions regulated by gray and white matter. Under this model, gender is the innate sense of ourselves arising from the neural electromagnetic fields of the interconnected networks of the reproductive axis (Author $1 \& 2$ (a), 2021).

Gender identity in the intersex and trans communities as separate from bodily sex, makes the notion of a single category of sex/gender awkward (Author $1 \& 2$ (a), 2021). The reproductive axis model of gender makes allowance for specific behaviors related to reproduction and emergent from the dimorphic limbic system. These behaviors are canalized and sufficiently polarized, yet with overlap on a gender spectrum (Author 1 \& 2 (a), 2021); in other words, gender is another canalized spectrum. Neural circuitry is involved in some sexually canalized tendencies as a function of an early hormone-dependent sex-specific brain organization (Wu \& Shah, 2011), and physiology relevant to reproduction is more canalized than general behavior and overlapping along spectra of sex and gender, most especially in behaviors relevant to reproduction, i.e., the care of offspring (Author $1 \& 2$ (a), 2021).

Canalization can be more simply defined as conventional identities huddled towards the ends of separate sex and gender spectra (author $1 \& 2$, (a), 2021). In this way and notwithstanding other influences, an XY fetus mostly produces a male inclined brain (gender) with latent adolescent sexuality, and an XX fetus mostly produces a female inclined brain (gender) with latent adolescent sexuality. Adolescence itself is a time of gender intensification (Jones \& Lopez, 2013), be it increased contentment or morbid discontent (dysphoria),

Thus, gender, as innate trait expression related to reproduction, is likely the spectrum of figure 4 between feminine and masculine endpoints (Sanchez, \& Vilain, 2010).

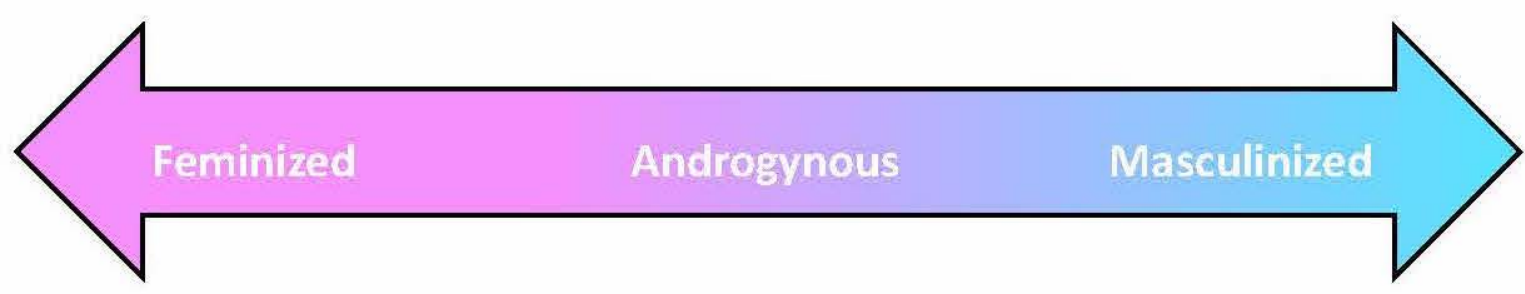

(insert figure 4 here)

Figure 4. Existential sense of self that provides a biological drive to behavior (innate cognitions \& emotions, the Id). Biologically and pre-natally fixed, most likely post-natally flexible to some degree. It is the biologically determined sense of ourselves and demonstrated in the pre-verbal stages of childhood.

Innate gendered behaviors may be clustered or canalized towards dominant endpoints within the reproductive axis (Author $1 \& 2$ (a) 2021. A sizable degree of shift between bodily sex and innate gender is problematic and can result in incongruence with or without gender dysphoria.

\section{Androgyny}

Androgyny has been an important part of identity research (Vantieghem \&Vermeersch, 2014), however, cultural changes, support for the masculine model, and conflation of terminology has led many researchers to abandon the notion of androgyny (Kark, 2020). How can we represent androgyny if femininity and masculinity are a single continuum? Androgyny has two forms, physical and psychological. Firstly, a biological spectrum of innate gender from feminine to masculine endpoints raises the probability of an innately androgynous brain (see figure 4 above). 
Others have referred to this androgyny as a form of neural intersex common to all brains (Joel, 2011).

\section{Androgynous, Intersexed, or Non-Binary Brains}

Anemonefish brains appear to be bipotential and a neurological sex change from male to female before gonad development has been observed. This process seems to be orchestrated intrinsically in the brain itself. "Fluctuating plasma levels of gonadal hormones do not appear necessary for feminization of the brain" (Dodd et al., 2019, p. 75). Could this have any relevance in humans?

The androgynous brain or neural intersex promoted as common to all brains (Joel, 2011) may be understood differently. Following the fact that the numbers of adults other than the cis-gendered are anywhere from $3-10 \%$ of the world's population (Williams Institute, 2018; Farr, Simon, \& Bruun, 2017), we can observe most individuals live with the ability to coordinate behavioral responses with physiological processes in response to sexually relevant cues (Simerly, 2002), thus ensuring the continuation of the species. So when we canalize gender along a spectrum, we can reasonably assume an innately androgynous brain belongs to only a few whose innate gender is positioned more centrally on the spectrum. The probability of innately androgynous or intersex brains warrants an explanation.

The spectrum model of sex and gender agrees that the complex intricacies of the social and cultural influences on sexuality make sex and gender nearly impossible to explore fully (Ganna et al., 2019). Nevertheless, within the bio-psycho-social theory of development, we may more easily delineate sex and gender (Wood \& Eagly, 2002) where the brain itself is in part neuroplastic and where sustained neural activity can push the brain and mind to change to some degree (Doidge, 2008; Kaiser, 2012; Isles, 2015). An innately androgynous gender (brain sex) may lay dormant as it were, waiting for distal forces, such as parents or society, to move it toward a more male or female becoming, or not. If the case of female-to-male (FtM) individuals assigned female at birth who are dysphoric about having breasts but content with female genitalia, and whose dysphoria dissipates after bilateral mastectomy, may feel a push to differentiate their androgyny towards one end of the gender spectrum, or not and remain undifferentiated. We would suggest this sequence is the biology behind non-binary gender identity. In either case, their gender identity can be biological without being dimorphic.

Similarly, non-binary male-to-female (MtF) trans individuals may choose to retain their male genitalia when it does not feel dysphoric to do so and may identify anywhere along the spectrum of gender. Furthermore, the individual strength of expression of trans identities along a spectrum, is likely dependent on multifactorial interactions such as prenatal hormones and numbers of corresponding receptors (see later). All identities can express sexuality anywhere along a spectrum of sexual orientation (see figure 5 below).

Children with an unofficial gender about the androgynous center of the brain sex spectrum may indeed be neurologically intersex, yet, if not obviously dysphoric, raised to some degree and in line with flexibility theory (Sporns, 2011; Yao, Bergan, Lanjuin, \& Dulac, 2017; Menger, Bettscheider, Murgatroyd, \& Spengler, 2010; Doidge, 2008) into whichever gender role is chosen for them - obviously determined by apparent bodily sex. Thus, an early androgynous gender becomes differentiated more towards the pink or blue end of the gender spectrum.

The second form of androgyny is physical and merely undifferentiated overt expression, usually in the form of clothing, hair style, etcetera (see later). 


\section{Sexuality as a Spectrum}

\section{Sexual Orientation}

As far back as 1953, infinite variability in sexual orientation was prescient in the controversial Kinsey Heterosexual-Homosexual Scale, which represented a 'spectrum' of orientation that implied endpoints with a bisexual centre.

There is a growing body of research supporting the claim that sexual orientation or attraction is not a categorical binary, nor trilogy (heterosexual, bisexual, homosexual), but rather, falls along a spectrum of orientation (Savin-Williams, Cash, McCormack, \& Rieger, 2017; Savin-Williams, 2014; Lee et al., 2016; Wang et al., 2019). Within the rubric of bisexuality alone, there is an extensive range of sexual characteristics (Savin-Williams, 2016). The spectrum model accounts for an overall variability in sexual orientation.

According to Freud, humans are innately either polymorphous or bisexual (Dvorsky \& Hughes, 2008). Sexual orientation is likely pre-natally determined (Barron, \& Hare, 2020; Rice, Friberg, \& Gavrilets, 2012; Meyer-Bahlburg, 2019) while leaving room for some post-natal flexibility (Freud, 1966). For example, many women experience desires for either men or women under certain circumstances, regardless of their overall sexual orientation (Bailey et al., 2016). Sexual fluidity becomes apparent when, in gay and lesbian populations following some form of therapy, a change in sexual orientation has been observed (Spitzer, 2003).

Sigmund Freud was the first academic to elaborate on the primary function of intimacy or sexual attraction as a way of emotional bonding; its secondary purpose is to procreate (Freud, 1966). Others affirm sexuality is not intrinsically grounded solely in lustful activity and highlight how intimate romance can affirm bonding, commitment, and attachment (Feybesse, \& Hatfield, 2015).

A pattern of sexual orientation fluidity amongst sexual minority women has been documented (Mock \& Eibach, 2012). A post-operative change in sexual orientation is frequent among transgender individuals (Auer, Fuss, Höhne, Stalla, \& Sievers, 2014). Freud would be pleased.

Sexual orientation is not necessarily tethered to bodily sex and in this current paper lies anywhere along a spectrum representing homosexual, through bisexual, to heterosexual, and as represented by Figure 5.

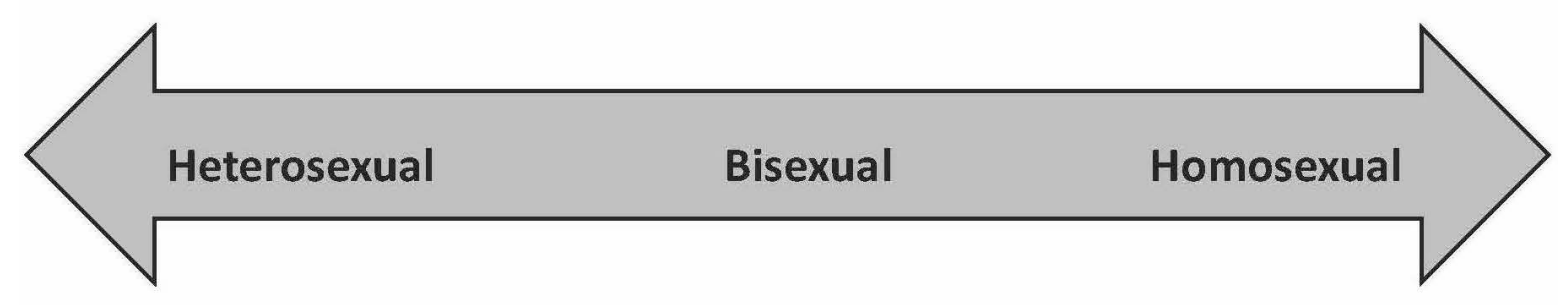

(insert figure 5 here)

Figure 5. Sexual orientation has both a biological and psychological component and refers to whether we are sexually attracted to the opposite sex, the same sex, both, or none. Pre-natally variable, post-natally capricious (susceptible to change). Probably biologically determined but also under some psychological influence.

Sexual Drive (Libido)

No matter how we express sexual orientation, sexual arousal, or drive, is the same biological process driven by testosterone in all humans (van Anders, 2009). 
Testosterone and estrogen levels play a direct role in sex drive, and fluctuating levels can be the cause of daily and monthly fluctuations in libido (Ruiz-Cortes, 2012; van der Dennen, 2005; Riley \& Riley, 2000). Obesity can influence libido (van der Valk et al., 2019; Younis, El-Esawy, Salem, \& Eid, 2017), as can medications (Burger, 2016), anxiety or depression (Montejo, Montejo, \& Baldwin, 2018), stress (Edwards, Kumar, \& Nöldner, 2016), poor body image (Ivanov, Caceres, Buffington, Wiercinski, \& Centers, 2016), low self-esteem (Unal, Onur, Karsidag, \& Bakir, 2017; Diniz, Diniz, \& Trigueiro, 2019), or a history of sexual abuse (Care, 2017).

The variability in sexual drive is modeled in this paper from asexual through allosexual to hypersexual and represented by figure 6 .

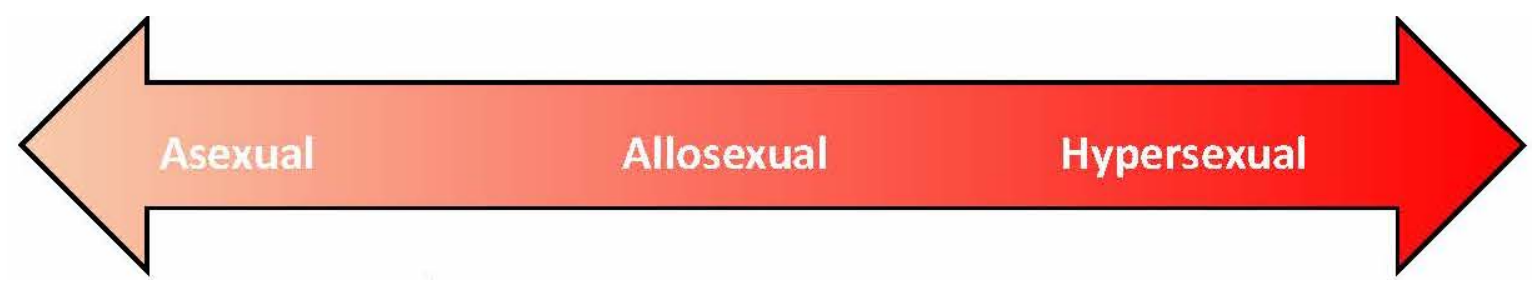

(insert figure 6 here)

Figure 6. Infinite variability in sexual drive is modeled as a spectrum from asexual, through allosexual, on to hypersexual. A person can be heterosexual and be anywhere from asexual (inactive) to hypersexual (hyperactive).

Similarly a person can be bisexual or homosexual from inactive to hyperactive. Being allosexual is often placed in the same class as other marginalized and medicalized groups; when expressed less pejoratively, it is merely on one end or the other of the spectrum, with or without dysfunction. Being allosexual is often conceptualized as the absence of sexual identity, whereas here, allosexual aligns with the absence of sexual expression (libido) in any orientation. As noted, at the individual level, of course, sexual drive may vary from time to time, even from day to day.

\section{Gender-Roles As A Spectrum}

From the beginning of this work, identity is a multifactorial human state comprised of sex, gender, sexual orientation, sexual drive (libido), and gender-roles. Identity is not discussed in terms of race, nationality, or group identity and does not include individual personality as personality is the combination of temperament, personal health, personal experience, and cultural background.

Apart from natural reflexes, there are ways of conducting ourselves that are more or less innate (Author $1 \& 2$, (a) 2021), and there are behaviors we learn (Hyde et al., 2019; Joel \& McCarthy, 2017). There are divergent ways to conceptualize gender-roles because such roles may include behavior based on innate traits and learned differences.

Following Kitcher's 'interactionist consensus' of behavior, traits are regarded as innate and peculiar to the individual and develop through the interaction of genome and environment (Kitcher 2001). In this way, traits are added to by experience creating broader behavior, making the sum total of behavior a performance influenced both from within by our brain-sex (Jones \& Lopez, 2013; Hines, 2017), and without via learned behavior. Furthermore, the ideological dictates of our culture's gender roles constrain or enhance behavior (Author $1 \& 2,2004$ ).

Innate gender-roles are culturally related to the divergent neurological tendencies between the sexes, as others have suggested (see Pfaff, 2011; Owen-Blakemore et al., 2009; Bartky, 1999; Buss, 1995). Learned roles or gender performance includes acquiring how to 'do' gender, i.e., how to present your gender to the outside world (Moore, 2010; Hefner, Rebecca, \& Oleshansky, 1975; Carothers, \& Reiss, 2013). It is self-evident we are born with the broad mosaic of human 
potentials as others have claimed (Joel \& McCarthy, 2017), yet social scripts will have us "do" or choose a gendered behavior that excludes some of that potential, that is, have us repress some of those traits (Butler, 1990). The anthropological sum of history signifies that "doing" gender involves gender roles and gender displays that focus on the behavioral aspects of being male or female (Fausto-Sterling, 1997; West \& Zimmerman, 2000).

Kessler wishes away the significance of genitals in gender attribution when she asserts that we observe gender cues without access to genitals (Kessler, 1998). However, a double negative seems appropriate here to say you cannot choose not to participate in gender because if you don't someone else will do it for you (Butler, 1990). We still punish those who cross the boundaries and fail to "do" their gender correctly (Butler, 1990).

Doing or performing gender (Butler, 1990) includes speech, mannerisms, body language, and other stereotypical behavioral traits. People demonstrate enormous variability across time and with any admixture possible. Within our childhood social settings, we learn our culture's genderroles, which consist of overt behavior deemed appropriate for our body's apparent sex. Thus, learned gender focuses on the visual aspects of being male or female, where we learn how to present a gendered self. On the other hand, cognition related to the brain's high function area has been labelled initially intersex, and not dimorphic (Hyde et al., 2018; Joel \& McCarthy, 2017; Rippon, Jordan-Young, Kaiser, \& Fine, 2014). Similarly, intelligence levels do not appear sexually dimorphic but rather as a mosaic (Halpern \& Wai, 2020).

Gender-roles involve gender displays that focus on the overt aspects of being male or female, such as body language, speech, clothing, phonation, and mannerisms. In this way, our identity is tethered to society and expressed through our behavior.

Figure 7 can represent this wide variety of behavioral expression. An individual can present an overt androgynous exterior, but that does not necessarily equate with psychological androgyny (Author $1 \& 2$ (c), in preparation).

Considering the flexibility inherent in much of human behaviour (Isles, 2015; Doidge, 2008), the willingness to cross traditional gender role boundaries can remain the cornerstone of both physical and psychological androgyny (Martin, Cook, \& Andrews, 2017) and represented by figure 7 .

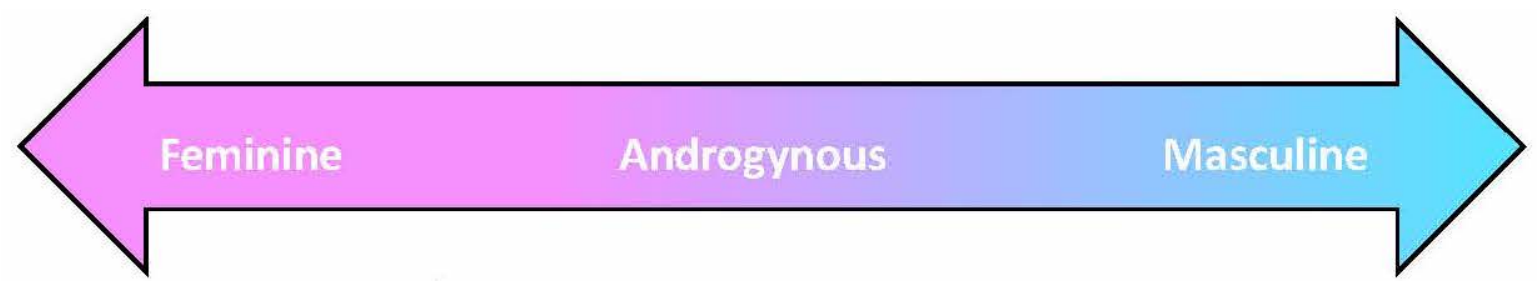

(insert figure 7 here)

Figure 7. Gender role as a spectrum; a phenotype

\section{Neo-androgyny}

Unfortunately and confusingly, lay communities' understanding of androgyny is the overt appearance of non-binary gender. Furthermore, generalized confusion into gender identity has resulted from conflating it with biological sex (Vantieghem \& Vermeersch, 2014). A form of neo-androgyny that has nothing to do with either sex or gender, consists of the adoption of 
learned and flexible behaviors such as "Social Efficacy, Creativity, Capability, Eminence, and Determination" (author $1 \& 2$ (c), in preparation). This model has the sexed brain (gender) separate from the functional flexibility of learned behaviour and unrelated to reproduction.

\section{Degrees of variability}

Variability can be in the degree to which regions are either masculinized or feminized - both within and between individuals. The variable range of regulation guarantees human diversity (McCarthy et al., 2015). According to O'Hanlan (2018), there are 3 to the thirty-seventh power or over 450 quadrillion possibilities of variation. In contrast, the same cannot be said of the reproductive tract, where reproductive genotypes and phenotypes are strictly binary (McCarthy et al., 2015).

Following fetal DNA encoding, and genetic and chromosomal determination (XX or XY), the extent of phenotypical development, i.e., the individual strength of expression of traits along a spectrum, is likely dependent on multifactorial interactions. For example, from levels of innervation and dendric spine density in organ systems, both healthy (Domnic sdfsadf; McCarthy, Forger, \& de Vries, 2017; Simerly, 2002), and disordered (Rylaarsdam, \& Guemez-Gamboa, 2019), and perhaps even in the synaptic connections between cells (Jones \& Lopez, 2013). And furthermore, dependent of levels of synergetic or antagonistic hormone exposure pre- (Ristori et al., 2020; Hines, 2020) and post-natally (Fernandez et al., 2020; Champagne \& Curley, 2016; Goddings et al., 2014; Meethal \& Atwood, 2005), and from the numbers of hormone receptors (see Denley, Gatford, Sellers, \& Srivastava, 2018; Halpern, 2013). The sex steroid estradiol, for example, has its specific "transduction cascade" involving kinases, enzymes, proteins, and epigenetic modifications. "A laundry list of all of the distinct cellular mechanisms mediating neuroanatomical and neurophysiological endpoints would fill pages and remain incomplete..." (McCarthy in Joel \& McCarthy, 2017, p. 381). And as we noted, estrogen and androgen receptors show high levels of distribution in the reproductive axis overall (Swaab, 2004; Sato et al., 2004; McEwen, 2001).

Additionally, within endpoints along any spectrum, there cannot be uniform masculinization or uniform feminization, resulting in infinite variation. Endpoints beyond hypermasculine or hyperfeminine are dysfunctional. This intrinsic limitation maintains canalized human phenotypes within their reproductive range (Joel \& McCarthy, 2017)

\section{Discussion}

Despite ethnohistorical accounts of multiple genders throughout various localities across North America (Pate, 2004) and in many other countries, identity diversity has only recently become the discussion of the decade as it were. The world is recognizing a 'transgender moment' (Anderson, 2019). The spectrum model is not a means of measuring or mapping such a 'moment'; instead, it may prove useful in understanding human identity diversity overall and its increasingly awkward measurement and cataloging.

In contrast to the debates between radical social constructionism and radical gender essentialism, we can speculate via the notion of canalization that there is sufficient overlap in human genotypes and phenotypes to restrict the free-for-all labeling to a few polarized labels, such as the LGBTQI (lesbian, gay, bisexual, trans, queer, intersex) currently in use. Additionally, overly sophisticated models of identity could be suspect of theoretical overfitting, whereas simpler models may capture underlying structure better, and may thus have improved predictive performance (Smaling, 2005), especially if one considers Nature is not capricious. 


\section{Criticisms}

In researching the problematic identity development phenomenon, this article began with abductive reasoning originating in the Complexity - Simplicity principle. Such beginnings seek to find the simplest explanation. The use of these principles may tend towards unjustified reductionism, and simple laws may indeed seem at odds with the complexities of life. In defense, simple laws do not guarantee perfect theory; instead, they are merely adequate for reaching a more immediate goal for future research. The use of simplified theory can speed up the process of finding that elusive optimal, perfect, science-based solution when such a solution, such as the origins of identity diversity, remains out of reach.

A spectrum of anything describes its infinite number of positions between two endpoints. As such, criticism of identity as spectra may claim the terminology to match infinite identities would need to be infinite itself, i.e., there can be no end to the terminology representing identity as spectra, resulting in more confusion. In response, we can speculate traditional categorical boundaries of sex and gender are not hard and fast; instead, they are more reasonably "discrete" (Haslam, 2002, p. 217), in other words, moderately focused towards male and female endpoints and as such are sufficiently enveloped within the current LGBTQ labelling.

We claim there is sufficient overlap in the human phenotype to restrict the current spurious freefor-all labelling to a few polarized labels. As Haslam states, "Structures that cannot be accommodated under even the most expansive account of categories can be called continua" and "Although a binary distinction can be imposed on such a continuum, its placement is purely arbitrary" (Haslam, 2002, p. 204). This restriction would be similar to how the study of personality limited its unlimited taxons within the MBTI 16 types (Myers, McCaulley, \& Most, 1985), although, again, the MBTI has been criticized as too simplistic (Pittenger, 2005).

Further complicating the search for understanding developmental-psycho-biology, we should not separate Nature and nurture (Sweatt Nestler, Meaney, \& Akbarian, 2013). The sum of genetics, epigenetics, and our experiences, are all linked throughout our lives to shape our development and behavior; in other words, they are linked biologically, psychologically, and socially (Waddington, 1942/2012; Kitcher, 2001; McCarthy et al. 2009; McCarthy \& Nugent, 2015; Auger, \& McCarthy, 2017).

Social learning of difference may begin at birth or earlier if the sex of a child is known beforehand (see Author $1 \& 2$ (a) 2021). Before a newborn has a chance to take their first breath, the environment has already played a role in their life (Rose, 2010). In this vain, problems arise in studies using known groups to determine how variation affects identity diversity, as they can only produce correlational results, and correlational outcomes are not relevant to looking at causation as they are post hoc. Post hoc subjects have undergone the confounds of already having lived in a social world. Further, human fetal studies testing outcomes of interference in-utero are unethical, while post-mortem studies are also correlational and 'after the fact' of living.

\section{Conclusion}

The aim of this paper was to examine complex spectrum theory that include gender and other facets of identity aligned along spectra. Without denying the complexity within, we chose to see if a more simplistic contribution to visualizing the infinite expression of identity that remained scientifically grounded was plausible.

The interaction of genes (sex and autosomal chromosomes), hormones (gonadal and others), and environment, both in utero and throughout life, creates human variability (Joel, 2011).

Conventional humans are born within taxa or canalized spectra of innate anatomical and cerebral 
differences relevant to reproduction. These differences are not strictly dimorphic; instead, they are discretely canalized and huddled towards spectral endpoints. Most other behavior is available to both sexes due to overlap in male and female neuroanatomy and neurophysiology unrelated to reproduction.

There is currently no grand unifying theory that provides a science-based rationale for the existence of variation in the human phenotype, nor the shared origins of both conventional and unconventional human identities alike. As yet, undetermined combinations of genetic, epigenetic, hormonal, psychological, and social factors likely operate together to determine what sex, gender, and sexuality an individual will express along the spectra presented herein.

We may now counter Myer's (2008) 'dusk,' with everything based on genes, hormones, and learned behavior is representable along spectra, and that between male and female, there is arguably every one of infinite variation. A parsimonious theory that unifies the minimalist spectra presented herein may further provide understanding of human diversity, devoid of limitless labels, politics, religion, feminism, or radicalism.

Interestingly, data from honeybee genome sequencing shows how genetic predispositions to phenotypically distinct neuroanatomy and behaviors are epigenetically linked (Kohl, 2012). Any realistic broad-spectrum model of sex-specific differences needs to integrate the influence of the environment on brain development and function (Ratnu, Emami, \& Bredy, 017). The increasing discoveries of intersex animals and trans people have been attributed to raised environmental levels of chemicals such as endocrine disruptors and synthetic hormones (Erickson-Schroth, L. 2013). Linked bio-psycho-social spectra may encapsulate a novel theory on the origins of human identity diversity in which genetic and epigenetic influence on the linkage may prove critical. The physiological linking of these spectra may assist in evaluating the shared origins of all human identity.

We have provided a scientifically grounded contribution to visualizing the infinite expression of identity diversity more simplistically than currently possible and presented several aspects of identity, including gender, as spectra lying within a canalized range of variation. Interlinking these spectra may assist in evaluating the shared origins of all human identity.

\section{Declarations}

Human and Animal Rights: This article does not contain any studies with human participants or animals performed by the authors.

This research did not receive any specific grant from funding agencies in the public, commercial, or not-for-profit sectors.

Conflict of interest: The authors declare they have no conflicts of interest.

CRediT author statements.

Author 1: Conceptualization; Project administration; Resources; Software; Writing - original draft \& editing; Writing - review \& editing.

Author 2: Project administration; Writing - review \& editing. 


\section{References.}

Abed, E., Schudson, Z., Gunther, O., Beischel, W., \& van Anders, S., (2019). Sexual and Gender Diversity Among Sexual and Gender/Sex Majorities: Insights via Sexual Configurations Theory. Archives of sexual behavior, pp.1-19.

Ainsworth, C. (2015). Sex redefined. Nature, 518(7539), 288.

Anderson, R. (2019). When Harry Became Sally: Responding to the Transgender Moment. Encounter Books.

Ansara, Y. (2010). Beyond cisgenderism: Counselling people with non-assigned gender identities. Counselling ideologies: Queer challenges to heteronormativity, 167-200.

Ao, Y., Ouyang, Y., Yang, C., \& Wang, Y. (2021). Global Signal Topography of the Human Brain: A Novel Framework of Functional Connectivity for Psychological and Pathological Investigations. Frontiers in Human Neuroscience, 15, 147.

Auer, M., Fuss, J., Höhne, N., Stalla, G., \& Sievers, C. (2014). Transgender transitioning and change of self-reported sexual orientation. PLoS One, 9(10), p.e110016.

Auger, A., \& McCarthy, M. (2017). Epigenetic Contribution to Sex Differences in Hormones, Brain and Behavior (Third edition).

Author 1, \& Author 2 (a) (2021). Sex vs Gender: A Biological Location for Gender, not Sex. Cambridge Open Engage. doi:10.33774/coe-2020-k7gt1-v4 This content is a preprint and has not been peer-reviewed.

Author 1, \& 2 (b). (in preparation). Sex and gender diversity: Multidimensional linkage of five unidimensional spectrums of identity.

Author 1, \& 2 (c). (in preparation). Androgyny, shaken, not stirred: De-gendering psychological androgyny theory.

Author $1 \&$ 2. (2004). Positive and negative androgyny and their relationship with psychological health and well-being. Sex Roles, 48(11-12), 555-565.

Bailey, J., Vasey, P., Diamond, L., Breedlove, S., Vilain, E., \& Epprecht, M. (2016). Sexual orientation, controversy, and science. Psychological Science in the Public Interest, 17(2), 45-101.

Bao, A., \& Swaab, D. (2011). Sexual differentiation of the human brain: relation to gender identity, sexual orientation and neuropsychiatric disorders. Frontiers in neuroendocrinology, 32(2), 214-226.

Barron, A., \& Hare, B. (2020). Prosociality and a sociosexual hypothesis for the evolution of same-sex attraction in humans. Frontiers in Psychology, 10, 2955.

Bartky, S. (1999). Femininity and domination. In C. C. Gould (Ed.), Key concepts in theory: Gender. Humanity Books.

Blackless, M., Charuvastra, A., Derryck, A., Fausto-Sterling, A., Lauzanne, K. \& Lee, E. (2000). How sexually dimorphic are we? Review and synthesis. American Journal of Human Biology: The Official Journal of the Human Biology Association, 12(2), pp.151-166.

Blanchard, R. (1989). The concept of autogynephilia and the typology of male gender dysphoria. Journal of Nervous and Mental Disease.

Blecher, S., \& Erickson, R. (2007). Genetics of sexual development: A new paradigm. American Journal of Medical Genetics, 143A, 3054-3068. 
Burger, J. (2016). Side Effects of Medications and Mitigation Strategies. Intimacy Post-injury: Combat Trauma and Sexual Health, 87.

Buss, D. (1995). Evolutionary Psychology: A new paradigm for psychological sciences. Psychological Enquiry, 6, 1-30.

Butler, J. (1990). Gender trouble: Feminism and the subversion of identity. New York: Routledge. Care, S. (2017). Survivors of sexual abuse. Mayes' Midwifery E-Book, 201.

Carothers, B., \& Reiss, H. (2013). Men and women are from earth: Examining the latent structure of gender. Journal of Personality \& Social Psychology, 104, 2, 385- 407. 10 1037/a0030437

Beauvoir, Simone de, The Second Sex, trans. by H. M. Parshley (London: Vintage, 1997). van der Dennen, J. (2005). Introduction to The Nature of the Sexes. In The Nature of the Sexes: The Sociobiology of Sex Differences and the 'Battle of the Sexes'.

Devor, H. (1994). Toward a taxonomy of gendered sexuality. Journal of psychology \& human sexuality, 6(1), 23-56.

Diamond, M. (2009). Clinical implications of the organizational and activational effects of hormones. Hormones \& Behavior, 55, 621-632.

Diniz, E., Diniz, G. \& Trigueiro, E. (2019). Sexual libido of the elderly woman: myth of asexual old age. MOJ Gerontol Ger, 4(1), 28-30.

Doidge, N. (2008). The brain that changes itself. Scribe.

Dodd, L., Nowak, E, Lange, D., Parker, C., DeAngelis, R., Gonzalez, \& Rhodes, J. (2019). Active feminization of the preoptic area occurs independently of the gonads in Amphiprion ocellaris. Hormones and behavior, 112, 65-76.

Dvorsky, G., \& Hughes, J. (2008). Postgenderism: Beyond the gender binary. Institute for Ethics and Emerging Technologies, 20, 44-57.

Edwards, D., Kumar, V., \& Nöldner, M. (2016). P-01-051 Stress-induced sexual dysfunction in rodents and humans: the Rhodiola rosea extract WS ${ }^{\circledR} 1375$ shows clinical promise. The Journal of Sexual Medicine, 13(5), S158.

Eliot, L., Ahmed, A., Khan, H., Patel, J. (2021). Dump the "dimorphism": Comprehensive synthesis of human brain studies reveals few male-female differences beyond size. Neuroscience \& Biobehavioral Reviews, in press. doi.org/10.1016/j.neubiorev.2021.02.026.

Ellis, L., Hershberger, S., Field, E., Wersinger, S., Pellis, S., Geary, D., ... \& Karadi, K. (2008). Sex Differences: Summarizing More than a Century of Scientific Research. North Charleston, South Carolina, Amazon.

Erickson-Schroth, L. (2013). Update on the biology of transgender identity. Journal of Gay \& Lesbian Mental Health, 17(2), 150-174.

Farr, R. Simon, K.., \& Bruun, S. (2017). LGBTQ relationships: Families of origin, same-sex couples, and parenting. In Family Dynamics and Romantic Relationships in a Changing Society (pp. 110-136). IGI Global.

Feybesse, C., \& Hatfield, E. (2015). The dark side of love: Brazil. Interpersonal relationships: Conceptions and context of intervention and evaluation.

Francis, B. (2012). Gender monoglossia, gender heteroglossia: the potential of Bakhtin's work for re-conceptualising gender. Journal of Gender Studies, 21(1), 1-15. 
Freud, S. (1966). Project for a scientific psychology (1950 [1895]). In The Standard Edition of the Complete Psychological Works of Sigmund Freud, Volume I (1886-1899): Pre-Psycho-Analytic Publications and Unpublished Drafts (pp. 281-391).

Ganna, A., Verweij, K. J., Nivard, M. G., Maier, R., Wedow, R., Busch, A. S., ... \& Zietsch, B. P. (2019). Large-scale GWAS reveals insights into the genetic architecture of same-sex sexual behavior. Science, 365(6456).

García-Acero, M., Moreno-Niño, O., Suárez-Obando, F., Molina, M., Manotas, M., Prieto, J., ... $\&$ Rojas, A. (2020). Disorders of sex development: Genetic characterization of a patient cohort. Molecular medicine reports, 21(1), 97-106.

Guillamon, A., Junque, C., \& Gómez-Gil, E. (2016). A Review of the Status of Brain Structure Research in Transsexualism. Archives of Sexual Behavior, 45:1615-1648.

Halpern, D., \& Wai, J. (2020). Sex Differences in Intelligence. In R. Sternberg (Ed.), The Cambridge Handbook of Intelligence (Cambridge Handbooks in Psychology, pp. 317-345). Cambridge: Cambridge University Press. doi:10.1017/9781108770422.015

Haslam, N. (2002). Kinds of kinds: A conceptual taxonomy of psychiatric categories. Philosophy, Psychiatry, \& Psychology, 9(3), 203-217.

Hefner, R., Rebecca, M., \& Oleshansky, B. (1975). Development of sex-role transcendence. Human Development, 18, 143-158.

Hines, M. (2017). Gonadal Hormones and Sexual Differentiation of Human Brain and Behavior. Hormones, Brain, and Behaviour, 3(5), 247-278, doi.org/10.1016/B978-0-12-803592-4.00103-6

Hyde, J., Bigler, R., Joel, D., Tate, C., \& van Anders, S., (2019). The future of sex and gender in psychology: Five challenges to the gender binary. American Psychologist, 74(2), p.171.

Imhoff, R., Banse, R., \& Schmidt, A. (2017). Toward a theoretical understanding of sexual orientation and sexual motivation. Archives of sexual behavior, 46(1), 29-33.

Isles, A. (2015). Neural and behavioral epigenetics; what it is, and what is hype. Genes, Brain \& Behavior, 14(1), 64-72.

Ivanov, O., Caceres, A., Buffington, C., Wiercinski, K., \& Centers, N. (2016). Effects of riskreducing surgery on libido, self-image, and psychological status among BRCA mutation carriers.

Joel, D. (2011). Male or female? Brains are intersex. Frontiers of Intergretive Neuroscience, 5, 19. doi: $103389 /$ fnint 201100057

Joel, D. (2012). Genetic-gonadal-genitals sex (3G-sex) \& the misconception of brain and gender, or, why 3G-males and 3G-females have intersex brain and intersex gender. Biology of sex differences, 3(1), 27

Joel, D., Berman, Z., Tavor, I., Wexler, N., Gaber, O., Stein, ... \& Liem, F. (2015). Sex beyond the genitalia: The human brain mosaic. Proceedings of the National Academy of

Sciences, 112(50), pp.15468-15473.

Joel, D., \& McCarthy, M. (2017). Incorporating sex as a biological variable in neuropsychiatric research: where are we now and where should we be?. Neuropsychopharmacology, 42(2), 379.

Jones, R., \& Lopez, K. (2013). Human reproductive biology. Chapter Sixteen. Academic Press. doi.org/10.1016/B978-0-12-382184-3.00016-7

Kaiser, A. (2012). Re-conceptualizing "sex" and "gender" in the human brain. Zeitschrift für Psychologie, 220(2), 130-136, doi: 10.1027/2151-2604/a000104 
Kark, R. (2020). Androgyny. Encyclopedia of personality and individual differences, 160-166.

Kessler, S. (1998). Lessons from the Intersexed. Rutgers University Press.

Kinsey A, Pomeroy, W., \& Martin, C. (1948/1979). Sexual behavior in the human male. Indiana University Press.

Kitcher, P. (2001). Battling the undead: How (and how not) to resist genetic determinism (pp. 396-414). Cambridge University Press.

Knowles, J., \& Reed, C. (2019) How Sex Got Screwed Up. Wilmington: Vernon Press.

Kohl, J. (2012). Human pheromones and food odors: epigenetic influences on the socioaffective nature of evolved behaviors. Socioaffective Neuroscience \& Psychology, 2(1), p.17338.

Kappou, K., Ntougia, M., Kourtesi, A., Panagouli, E., Vlachopapadopoulou, E., Michalacos, S., ... \& Tsitsika, A. (2021). Neuroimaging Findings in Adolescents and Young Adults with Anorexia Nervosa: A Systematic Review. Children, 8(2), 137.

Lee, P., Nordenström, A., Houk, C., Ahmed, S., Auchus, R., Baratz, A... \& Mazur, T., (2016). Global disorders of sex development update since 2006: perceptions, approach and care. Hormone research in paediatrics, 85(3), pp.158-180.

Lin, J., Xu, H., Chen, B., Wang, W., Wang, L., Sun, X., \& Sang, Q. (2020). Expanding the genetic and phenotypic spectrum of female infertility caused by TLE6 mutations. Journal of assisted reproduction and genetics, 37(2), 437-442.

Mardell, A. (2016). The ABC's of LGBT+. Mango.

Martin, C., Cook, R., \& Andrews, N. (2017). Reviving androgyny: A modern day perspective on flexibility of gender identity and behavior. Sex Roles, 76(9), 592-603.

Matsui, T., Li, L., Wu, J., Cook, S., Nagoshi, T., Picard, M., ... \& Rosenzweig, A. (2002).

Phenotypic spectrum caused by transgenic overexpression of activated Akt in the heart. Journal of Biological Chemistry, 277(25), 22896-22901.

McCarthy, M., Auger, A., Bale, T., De Vries, G., Dunn, G., Forger, N ... \& Wilson, M. (2009). The epigenetics of sex differences in the brain. Journal of Neuroscience, 29(41), pp.12815-12823.

McCarthy, M., De Vries, G., \& Forger, N. (2017). Sexual differentiation of the brain: a fresh look at mode, mechanisms, and meaning. Hormones, Brain and Behavior (Third Edition), 5, 3-32. doi: 10.1016/B978-0-12-803592-4.00091-2

McCarthy, M., Pickett, L., VanRyzin, J., \& Kight, K. (2015). Surprising origins of sex differences in the brain. Hormones and behavior, 76, 3-10.

McCarthy, M., \& Arnold, P. (2011). Reframing sexual differentiation of the brain. Nature Neuroscience, 14(6), 677-683.

McEwen, B. (2001). Invited review: Estrogens effects on the brain: multiple sites and molecular mechanisms. Journal of applied physiology, 91(6), 2785-2801.

McKenna, W. \& Kessler, S. (1977) Experimental design as a source of sex bias in social psychology. Sex Roles, 3(2), 117-128.

Meyer-Bahlburg, H. (2019). "Diagnosing" Gender? Categorizing Gender-Identity Variants in the Anthropocene. Archives of Sexual Behavior, 1-9.

Menger, Y., Bettscheider, M., Murgatroyd, C., \& Spengler, D. (2010). Sex differences in brain epigenetics. Epigenomics, 2(6), 807-821. 
Mock, S., \& Eibach, R. (2012). Stability and change in sexual orientation identity over a 10-year period in adulthood. Archives of sexual behavior, 41(3), 641-648.

Montejo, A., Montejo, L., \& Baldwin, D. (2018). The impact of severe mental disorders and psychotropic medications on sexual health and its implications for clinical management. World Psychiatry, 17(1), 3-11.

Montanez, A. (2017). Beyond XX and XY. Scientific American, 317(3), 50-5.

Moore, M. (2010). Human nonverbal courtship behavior-a brief historical review. Journal of Sex Research, 47(2-3), 171-180.

Myers, D. (2008). Social psychology (9th ed.). McGraw-Hill.

Myers, I., McCaulley, M., \& Most, R. (1985). Manual, a guide to the development and use of the Myers-Briggs type indicator. consulting psychologists press.

Owen-Blakemore, J., Berenbaum, S., \& Liben, L. (2009). Gender development. Psychology Press.

Palan, K, Areni, C., \& Kiecker, P. (1999). Re-examining masculinity, femininity, and gender identity scales. Marketing Letters, 10(4), 357-371.

Pate, L. (2004). The use and abuse of ethnographic analogies in interpretations of gender systems at Cahokia. In Ungendering civilization (pp. 85-107). Routledge.

Pittenger, D. (2005). Cautionary comments regarding the Myers-Briggs type indicator. Consulting Psychology Journal: Practice and Research, 57(3), 210.

Pfaff, D. (2011). Man and woman: An inside story. Oxford.

Rathus, S., Nevid, J., \& Fichner-Rathus, L. (2005). Human sexuality in a world of diversity. Boston: Allyn \&Bacon.

Ratnu, V., Emami, M., \& Bredy, T. (2017). Genetic and epigenetic factors underlying sex differences in the regulation of gene expression in the brain. Journal of neuroscience research, 95(1-2), 301-310.

Reeder, H. (2003). The effect of gender role orientation on same- and cross-sex friendship formation. Sex Roles, 49(3/4), 143.

Reilly-Cooper, R. (2016). Gender is Not a Spectrum. Retrieved from https://aeon.co/essays/theidea-that-gender-is-a-spectrum-is-a-new-gender-prison. Visited 18 April, 2021.

Riley, A., \& Riley, E. (2000). Controlled studies on women presenting with sexual drive disorder: I. Endocrine status. Journal of Sex \&Marital Therapy, 26(3), 269-283.

Rippon, G., Jordan-Young, R., Kaiser, A., \& Fine, C. (2014). Recommendations for sex/gender neuroimaging research: key principles and implications for research design, analysis, and interpretation. Frontiers in human neuroscience, 8, 650.

Rice, W., Friberg, U., \& Gavrilets, S. (2012). Homosexuality as a consequence of epigenetically canalized sexual development. The Quarterly review of biology, 87(4), 343-368.

Rosario, V. (2004). The biology of gender and the construction of sex? GLQ: A Journal of Lesbian \& Gay Studies, 10, 280-287.

Ruscio, J., \& Ruscio, A. (2008). Categories and dimensions: Advancing psychological science through the study of latent structure. Current Directions in Psychological Science, 17(3), 203207. 
Ruiz-Cortes, Z. (2012) Gonadal Sex Steroids: Production, Action and Interactions in Mammals. In: Sergej Ostojic (Eds.), Steroids -From Physiology to Clinical Medicine. 3-44.

Rylaarsdam, L., \& Guemez-Gamboa, A. (2019). Genetic causes and modifiers of autism spectrum disorder. Frontiers in cellular neuroscience, 13, 385.

Sanchez, F., \& Vilain, E. (2010). Genes and brain sex differences. Progressive Brain Research $186,65-76$.

Sato, T., Matsumoto, T., Kawano, H., Watanabe, T., Uematsu, Y., Sekine, K., ... \& Nakamichi, Y. (2004). Brain masculinization requires androgen receptor function. Proceedings of the National Academy of Sciences, 101(6), 1673-1678.

Savin-Williams, R. (2014). An exploratory study of the categorical versus spectrum nature of sexual orientation. The Journal of Sex Research, 51(4), 446-453.

Savin-Williams, R. (2016). Sexual orientation: Categories or continuum? Commentary on Bailey et al.(2016). Psychological Science in the Public Interest, 17(2), 37-44.

Savin-Williams, R., Cash, B., McCormack, M., \& Rieger, G. (2017). Gay, mostly gay, or bisexual leaning gay? An exploratory study distinguishing gay sexual orientations among young men. Archives of sexual behavior, 46(1), 265-272.

Schön, I., Martens, K., \& van Dijk, P. (2009). Lost sex. The evolutionary biology of parthenogenesis.

Schudson, Z., Dibble, E., \& van Anders, S. (2017). Gender/sex and sexual diversity via sexual configurations theory: Insights from a qualitative study with gender and sexual minorities.

Psychology of Sexual Orientation and Gender Diversity, 4(4), 422.

Simerly, R. (2002). Wired for reproduction: organization and development of sexually dimorphic circuits in the mammalian forebrain. Annual review of neuroscience, 25(1), 507-536.

Smaling, A., 2005. The Chatton-Ockham strategy; an alternative to the simplicity principle. In Worldviews, Science And Us (pp. 38-58).

Sow, D (2018). Science Shows Sex Is Binary, Not a Spectrum. Retrieved from https://www.realclearpolitics.com/articles/2018/10/31/science_shows_sex_is_binary_not_a_spect rum_138506.html. Visited 26 January, 2020.

Spence, J. (1984). Gender identity and its implications for the concepts of masculinity and femininity. In T. Sonderegger (Ed.), Nebraska symposium on motivation, vol. 32, pp. 59-95.

Spitzer, R. (2003). Can some gay men and lesbians change their sexual orientation? 200 participants reporting a change from homosexual to heterosexual orientation. Archives of sexual behavior, 32(5), 403-417.

Sporns, O. (2011). The human connectome: a complex network. Annals of the new York Academy of Sciences, 1224(1), 109-125.

Stern, B., Barak, B., \& Gould, S. (1987). Sexual identity scale: a new self-assessment measure. Sex Roles, 17(9), 503-519.

Stokman, M., Renkema, K., Giles, R., Schaefer, F., Knoers, N., \& Van Eerde, A. (2016). The expanding phenotypic spectra of kidney diseases: insights from genetic studies. Nature Reviews Nephrology, 12(8), 472.

Swaab, D. (2004). Sexual differentiation of the human brain: relevance for gender identity, transsexualism and sexual orientation. Gynecological Endocrinology, 19(6), 301-312. 
Swaab D., \& Bao A. (2016) Sexual Differentiation of the Human Brain in Relation to GenderIdentity, Sexual Orientation, and Neuropsychiatric Disorders. In: Pfaff D., Volkow N. (eds.) Neuroscience in the 21st Century. Springer, New York, NY.

Sweatt, J., Nestler, E., Meaney, M., \& Akbarian, S. (2013). An overview of the molecular basis of epigenetics. In: J. Sweatt, M. Meaney, \& E. Nestler (Eds.), Epigenetic regulation in the nervous system: Basic mechanisms and clinical impact. Academic Press. doi: 10 1016/B978-0-12391494-1 00001-X.

Tate, C., Youssef, C., \& Bettergarcia, J. (2014). Integrating the study of transgender spectrum and cisgender experiences of self-categorization from a personality perspective. Review of General Psychology, 18(4), 302-312.

Traschütz, A., Cortese, A., Reich, S., Dominik, N., Faber, J., Jacobi, H., ... \& RFC1 Study Group. (2021). Natural History, Phenotypic Spectrum, and Discriminative Features of Multisystemic RFC1 Disease. Neurology, 96(9), e1369-e1382.

Unal, G., Onur, O., Karsidag, C., \& Bakir, M. (2017). Evaluation of self-esteem and childhood trauma in patients with sexual disorders. European Psychiatry, 41, S852-S853.

Unger, R. K. (1997). Toward a redefinition of sex and gender. American Psychologist, 34(11), 1085 .

van Anders, S. (2009). Androgens and diversity in adult human partnering. Endocrinology of social relationships, 340-363.

van der Valk, E., van den Akker, E., Savas, M., Kleinendorst, L., Visser, J., Van Haelst, M., Sharma, A. \& van Rossum, E. (2019). A comprehensive diagnostic approach to detect underlying causes of obesity in adults. Obesity Reviews, 20(6), pp.795-804.

van Anders, S. (2015). Beyond sexual orientation: Integrating gender/sex and diverse sexualities via sexual configurations theory. Archives of Sexual Behavior, 1-37.

Waddington C. (1942/2012), The epigenotype, Endeavour, vol. 1 (pg. 18-20). Reprinted in International Journal of Epidemiology 41(1): 10-13.

Wang, Y., Wu, H. \& Sun, Z. (2019). The biological basis of sexual orientation: How hormonal, genetic, and environmental factors influence to whom we are sexually attracted. Frontiers in neuroendocrinology, p.100798.

Waller, N., \& Meehl, P. (1998). Multivariate taxometric procedures: Distinguishing types from continua. Thousand Oaks, CA: Sage.

Williams Institute, UCLA, (2018) LBGT population proportion. Retrieved formwilliamsinstitute.law.ucla.edu/visualization/lgbt-stats/?topic=LGBT\#about-the-data

Wood., W., \& Eagly, A. (2002). A cross-cultural analysis of the behavior of women and men: Implications for the origins of sex differences. Psychological Bulletin, 128, 699-727.

Wu, M., \& Shah, N. (2011). Control of masculinization of the brain and behavior. Current opinion in neurobiology, 21(1), 116-123.

Yao, S., Bergan, J., Lanjuin, A., \& Dulac, C. (2017). Oxytocin signalling in the medial amygdala is required for sex discrimination of social cues. Elife, 6, e31373.

Younis, I., El-Esawy, F., Salem, R., \& Eid, H. (2017). What Do Women Want: Factors Affecting Female Libido Human Andrology Factors Affecting Female Libido. Human Andrology, 7(1), 1523. 
Zietsch, B., Morley, K., Shekar, S., Verweij, K., Keller, M., Macgregor, S., ... \& Martin, N. (2008). Genetic factors predisposing to homosexuality may increase mating success in heterosexuals. Evolution and Human Behavior, 29(6), pp. 424-433.

Zaidi, Z. (2010). Gender differences in human brain: a review. The Open Anatomy Journal, (2), pp. $37-55$ 